УДК 547.466:543.2

DOI: $10.17308 / \mathrm{kcmf} .2019 .21 / 721$

Поступила в редакцию 15.01.2019

Подписана в печать 15.02.2019

\title{
МЕЖФАЗНОЕ РАСПРЕДЕЛЕНИЕ СОРБИНОВОЙ КИСЛОТЫ ПРИ ЭКСТРАКЦИИ СОПОЛИМЕРОМ N-ВИНИЛФОРМАМИДА С 1-ВИНИЛ-3,5-ДИМЕТИЛПИРАЗОЛОМ
}

\author{
(C) 2019 Н. Я. Мокшина ${ }^{* 1}$, О. А. Пахомова ${ }^{2}$ Г. В. Шаталов ${ }^{3}$, Д. П.Тарасов ${ }^{1}$ \\ ${ }^{1}$ ВУНЦ ВВС «Военно-воздушная академия им. проф. Н. Е. Жуковского и Ю. А. Гагарина» \\ ул. Старых Большевиков, д. 54 а, 394064 Воронеж, Российская Федерация \\ ${ }^{2}$ Елеикий государственный университет имени И. А. Бунина \\ ул. Коммунаров, д. 28, 399770 Елец, Липецкая обл., Российская Федераџия \\ ${ }^{3}$ Воронежский государственный университет \\ Университетская пл., 1, 394018 Воронеж, Российская Федераичия
}

\begin{abstract}
Аннотация. С целью изучения экстракции сорбиновой кислоты из объектов со сложной матрицей изучено межфазное распределение сорбиновой кислоты в системе сополимер N-винилформамид - 1-винил-3,5-диметилпиразол - хлорид аммония. Рассчитаны коэффициенты распределения и степень извлечения консерванта при различных соотношениях фаз и концентрации раствора сополимера. Установлено влияние $\mathrm{pH}$ на экстракцию сорбиновой кислоты, предложен механизм ее взаимодействия с экстрагентом. Определение сорбиновой кислоты в водно-солевой фазе осуществлено методом капиллярного электрофореза в выбранных условиях.
\end{abstract}

Ключевые слова: сорбиновая кислота, экстракция, водорастворимый сополимер, электрофоретическое определение.

\section{ВВЕДЕНИЕ}

Сорбиновая кислота (Е-200; $\mathrm{C}_{6} \mathrm{H}_{8} \mathrm{O}_{2}$ ) относится к пищевым добавкам-консервантам, характеризуется эффективным антимикробным действием, малотоксична, используется для консервирования фруктовых и овощных консервов, кондитерских, мясных и рыбных продуктов, соков и безалкогольных напитков. В разумных дозах сорбиновая кислота оказывает положительное влияние на человеческий организм, повышая иммунитет и способствуя детоксикации организма. Однако при употреблении Е-200 возможны кожные заболевания [1]. Для контроля содержания многих органических соединений в пищевых продуктах и напитках часто применяется жидкостная экстракция в различных вариантах [2]. Из литературных источников известен только один коэффициент распределения сорбиновой кислоты, установленный для системы 4-метилпентанон-2 - вода, равный 0.08 [3]. Такое значение коэффициента распределения свидетельствует о невозможности применения органических растворителей для извлечения сорбиновой кислоты.

Мокшина Надежда Яковлевна, e-mail: moksnad@mail.ru
Ранее нами установлена эффективность водорастворимых гомо- и сополимеров виниламидного ряда в качестве экстрагентов разнохарактерных органических соединений [4-6].

Цель работы - изучение механизма межфазного распределения сорбиновой кислоты в водных системах на основе сополимера $\mathrm{N}$-винилформамида (ВФ) с 1-винил-3,5-диметилпиразолом (ВДМП) и определение консерванта методом капиллярного электрофореза. Для решения поставленных задач нами изучено комплексообразование в системе, содержащей сополимер N-винилформамида, рассчитаны экстракционные характеристики сорбиновой кислоты. Разработана экстракционно-электрофоретическая методика определения кислоты в модельных водных раствоpax, включающая жидкостную экстракцию аналита раствором водорастворимого сополимера и электрофоретический анализ концентрата, которая позволяет определять консервант в пищевых продуктах, напитках и сырье большинства производств.

\section{ЭКСПЕРИМЕНТАЛЬНАЯ ЧАСТЬ}

На рис. 1 приведены структурные формулы сорбиновой кислоты и сополимера $\mathrm{N}$-винилформамид - 1-винил-3,5-диметилпиразол. Характерис- 
<smiles>C/C=C/C=C/C(=O)O</smiles>

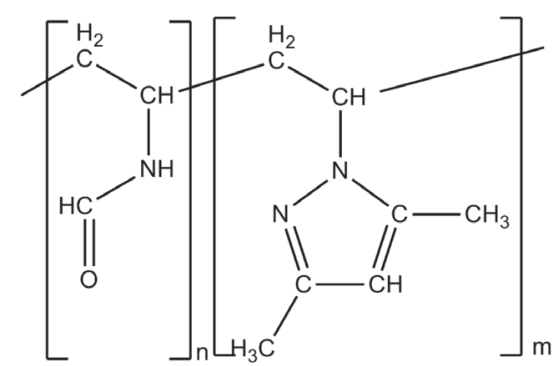

2

Рис. 1. Структурные формулы сорбиновой кислоты (1) и сополимера ВФ-ВДМП (2)

[Fig. 1. Structural formulas of sorbic acid (1) and copolymer of VF-VDMP (2)]

тическая вязкость сополимера составляла $0.40 \mathrm{dl} / \mathrm{g}$ при $20^{\circ} \mathrm{C}$ в растворе $0.2 \mathrm{M} \mathrm{NaCl}$. Радикальную сополимеризацию и анализ сополимера проводили в условиях, исключающих наличие кислорода воздуха, используя аргон, как и в случае [7].

В градуированных пробирках вместимостью $25 \mathrm{~cm}^{3}$ смешивали $10 \mathrm{~cm}^{3}$ раствора сорбиновой кислоты и водный раствор полимера в количестве, необходимом для установления соответствующих соотношений аналит-экстрагент. Для выделения самостоятельной органической фазы при экстракции сорбиновой кислоты применяли высаливатель (насыщенный раствор хлорида аммония). Экстрагировали на вибросмесителе в течение 10 минут при температуре $22 \pm 1{ }^{\circ} \mathrm{C}$. Для установления межфазного равновесия и полного расслаивания системы экстракционную систему центрифугировали при 10000 об/мин в течение 15 минут. Измеряли соотношение равновесных объемов водной $\left(V_{\text {в }}\right)$ и органической $\left(V_{\mathrm{o}}\right)$ фаз $\left(r=V_{\mathrm{B}} / V_{\mathrm{o}}\right)$. Водно-солевую фазу отделяли от органической и анализировали методом капиллярного электрофореза. Рассчитывали коэффициенты распределения (D) и степень извлечения $(R, \%)$ аналита согласно [5], результаты метрологически обработали (при $n=3, P=0.95$ ).

При проведении аналитических исследований по содержанию сорбиновой кислоты в качестве стандартных образцов применяли индивидуальные вещества фирмы Fluka Chemie GmbH. Готовили раствор препарата в дистиллированной воде, к полученному раствору добавляли $75 \mathrm{~g}$ высаливателя и при тщательном перемешивании доводили раствор до метки дистиллированной водой.

Определение сорбиновой кислоты проводили на системе капиллярного электрофореза «Капель-105М» с положительной полярностью высокого напряжения (внутренний диаметр капилляра $50 \mu \mathrm{m}$, общая длина $75 \mathrm{~cm}$ ). Отметим, что при рекомендуемых $40{ }^{\circ} \mathrm{C}$ наблюдается появление пика, мешающего определению сорбиновой кислоты, по- этому температуру повышали до $50{ }^{\circ} \mathrm{C}$, не меняя давление и длину волны детектирования. Для получения достоверных результатов одновременно с получением электрофореграммы регистрировали спектр поглощения сорбиновой кислоты в анализируемой пробе.

\section{РЕЗУЛЬТАТЫ И ИХ ОБСУЖДЕНИЕ}

Установлено влияние $\mathrm{pH}$ на экстракцию сорбиновой кислоты сополимером ВФ-ВДМП (табл. 1). Как следует из полученных данных, максимальная степень извлечения $R$ характерна для систем с $\mathrm{pH}$ ниже 5, разница с щелочным раствором составляет 80 \%. Поэтому все дальнейшие исследования проводили при $\mathrm{pH} 4.5$.

Для определения наиболее оптимальных условий экстракции сорбиновой кислоты варьировали соотношение объемов водной и органической фаз $(r)$, концентрации сополимера и аналита, $\mathrm{pH}$ водного раствора. Максимальная степень извлечения при однократной экстракции сорбиновой кислоты ( $\approx 95 \%)$ достигнута при следующих условиях: $r=10: 4 ; C_{\text {Вф-вдмп }}=0.15 \mathrm{~g} / \mathrm{cm}^{3}, \mathrm{C}_{\text {к-ты }}=0.045 \mathrm{~g} / \mathrm{cm}^{3}$, высаливатель - хлорид аммония (табл. 2).

За счет образования водородных связей при самоассоциации молекул увеличение концентрации сорбиновой кислоты может не приводить к повышению степени ее извлечения.

Таблица 1. Влияние $\mathrm{pH}$ на экстракцию сорбиновой кислоты сополимером ВФ-ВДМП $\left(T=20^{\circ} \mathrm{C}, n=3\right.$,

$$
P=0.95)
$$

[Table 1. The effect of $\mathrm{pH}$ on the extraction of sorbic acid with VF-VDMP copolymer $\left(T=20^{\circ} \mathrm{C}, n=3\right.$,

$$
P=0.95)]
$$

\begin{tabular}{|c|c|c|c|}
\hline № & $\mathrm{pH}$ & $D$ & $R, \%$ \\
\hline 1 & 4.0 & $70 \pm 2$ & 80.5 \\
\hline 2 & 4.5 & $94 \pm 2$ & 97.1 \\
\hline 3 & 7.5 & $15 \pm 1$ & 25.3 \\
\hline 4 & 8.5 & $12 \pm 1$ & 20.7 \\
\hline 5 & 9.5 & $5 \pm 0.6$ & 17.2 \\
\hline
\end{tabular}


Отметим, что сополимер ВФ-ВДМП оказался более эффективным экстрагентом по отношению к сорбиновой кислоте, чем ранее примененный нами сополимер $\mathrm{N}$-винилформамида с $\mathrm{N}$-винилимидазолом, в системе с которым степень извлечения едва превышала $90 \%$ [8].

Введение в систему компонента со звеньями ВФ приводит к образованию межмолекулярных $\mathrm{H}$-связей между -OH и >CO-группами сорбиновой кислоты и $\mathrm{N}$-атомами «пиридинового» типа экстр-

Таблица 2. Экстракционные характеристики межфазного распределения сорбиновой кислоты в системе ВФ-ВДМП (9:1), высаливатель хлорид аммония

[Table 2. Extraction characteristics of the sorbic acid interphase distribution in the VF-VDMP system (9:1), ammonium chloride desalter]

\begin{tabular}{|c|c|c|}
\hline $\begin{array}{l}\text { Концентрация сорбиновой } \\
\text { кислоты, г/мл } \\
\text { [The concentration of sorbic } \\
\text { acids, g/ml] }\end{array}$ & $D$ & $R, \%$ \\
\hline \multicolumn{3}{|c|}{$\begin{aligned} r & =10: 3 ; \mathrm{C}_{\text {ВФ-вдМП }}=0.24 \text { г/мЛ } \\
{[r} & \left.=10: 3 ; \mathrm{C}_{\text {VF-VDMP }}=0.24 \mathrm{~g} / \mathrm{ml}\right]\end{aligned}$} \\
\hline 0.015 & $11 \pm 0.8$ & 78.6 \\
\hline 0.025 & $13 \pm 1.1$ & 81.3 \\
\hline 0.030 & $13 \pm 1.4$ & 81.3 \\
\hline 0.035 & $15 \pm 2.1$ & 83.3 \\
\hline 0.040 & $25 \pm 2.2$ & 89.2 \\
\hline 0.045 & $26 \pm 2.1$ & 89.4 \\
\hline 0.050 & $24 \pm 2.4$ & 88.9 \\
\hline 0.015 & $11 \pm 0.8$ & 78.6 \\
\hline 0.025 & $13 \pm 1.1$ & 81.3 \\
\hline \multicolumn{3}{|c|}{$\begin{aligned} r & =10: 4 \mathrm{C}_{\text {ВФ-ВдмП }}=0.15 \text { г/мЛ } \\
{[r} & \left.=10: 4 \mathrm{C}_{\text {VF-VDMP }}=0.15 \mathrm{~g} / \mathrm{ml}\right]\end{aligned}$} \\
\hline 0.025 & $34 \pm 3.2$ & 93.2 \\
\hline 0.035 & $37 \pm 3.4$ & 93.4 \\
\hline 0.045 & $45 \pm 3.4$ & 94.7 \\
\hline 0.050 & $42 \pm 3.5$ & 94.4 \\
\hline \multicolumn{3}{|c|}{$\begin{aligned} r & =10: 2 ; \mathrm{C}_{\text {ВФ-ВДМП }}=0.20 \text { г/мЛ } \\
{[r} & \left.=10: 2 ; \mathrm{C}_{\mathrm{VF-VDMP}}=0.20 \mathrm{~g} / \mathrm{ml}\right]\end{aligned}$} \\
\hline 0.01 & $5 \pm 0.8$ & 51.0 \\
\hline 0.02 & $7 \pm 1.2$ & 53.8 \\
\hline 0.03 & $11 \pm 1.3$ & 68.8 \\
\hline 0.04 & $13 \pm 1.1$ & 72.2 \\
\hline \multicolumn{3}{|c|}{$\begin{aligned} r & =10: 5 ; \mathrm{C}_{\text {ВФ-ВДМП }}=0.18 \text { г/мЛ } \\
{[r} & \left.=10: 5 ; \mathrm{C}_{\text {VF-VDMP }}=0.18 \mathrm{~g} / \mathrm{ml}\right]\end{aligned}$} \\
\hline 0.01 & $7 \pm 1.3$ & 77.8 \\
\hline 0.02 & $10 \pm 1.8$ & 83.3 \\
\hline 0.03 & $16 \pm 1.6$ & 88.9 \\
\hline 0.04 & $18 \pm 2.2$ & 90.0 \\
\hline 0.05 & $28 \pm 2.1$ & 93.3 \\
\hline 0.06 & $32 \pm 2.5$ & 94.1 \\
\hline 0.07 & $26 \pm 2.8$ & 92.9 \\
\hline
\end{tabular}

агента. В образовании Н-связи возможно участие $>\mathrm{N}-\mathrm{H}$ и $>\mathrm{C}=\mathrm{O}$ групп в звеньях $\mathrm{N}$-винилформамида (рис. 2a).

Известно [9], что полимеры на основе N-виниламидов, содержащие поляризованную $>\mathrm{C}=\mathrm{O}$ группу, проявляют активность к взаимодействию с протонсодержащими соединениями, в том числе $\mathrm{c}-\mathrm{COOH} \mathrm{группами.} \mathrm{Под} \mathrm{влиянием} \mathrm{полярной}$ $>\mathrm{C}=\mathrm{O}$ группы макроцепи и $\mathrm{H}_{2} \mathrm{O}$ образуют цепочечные ассоциаты. В результате этого возможно взаимодействие атомов водорода и кислорода молекул воды как с соединениями с - $\mathrm{COOH}$ группами, выступающими в качестве доноров протонов, так и с веществами, имеющими $>\mathrm{C}=\mathrm{O}$ группу, выступающих в качестве акцепторов. Благодаря этому происходит образование сетки из водородных связей, что отражается на результатах экстракции (рис. $2 b$ ).

Учитывая данные [10] о том, что при экстракции происходит образование Н-связей между распределяемым веществами и экстрагентом, можно предположить, что в системе сорбиновая кислота - полимер комплексообразование возможно благодаря «сетке» водородных связей с участием поляризованных молекул воды в виде «мостиков»-ассоциатов между -OH и $>\mathrm{CO}$-группами аналита и функциональными группами полимеров.

Для определения сорбиновой кислоты после экстракции применяли метод внешнего стандарта с построением многоточечных градуировочных графиков. Для этого из стандартных растворов были приготовлены четыре градуировочных и снято восемь электрофореграмм (рис. 3). Электрофоретичес-

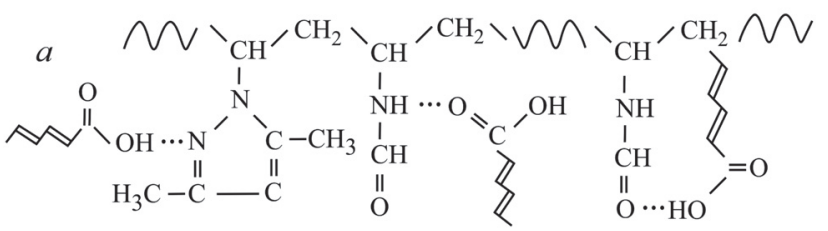

$b$

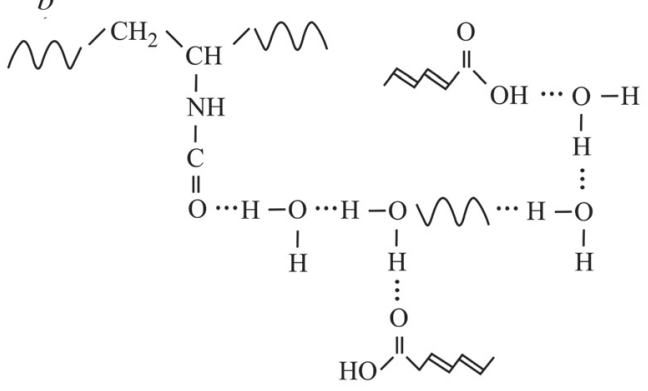

Рис. 2. Схема комплекса сорбиновая кислота ВФ-ВДМП

[Fig. 2. Scheme of the complex sorbic acid - VF-VDMP] 


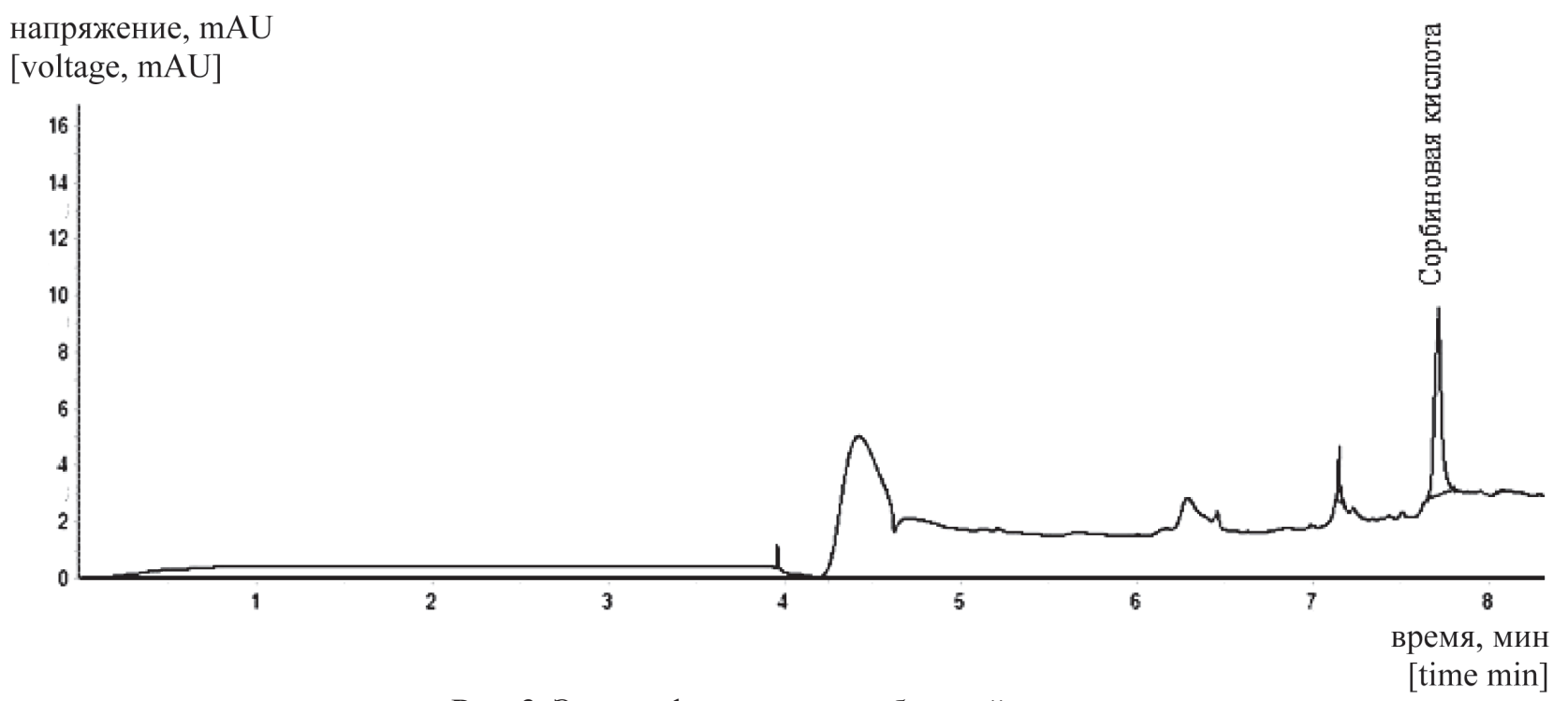

Рис. 3. Электрофореграмма сорбиновой кислоты

[Fig. 3. Electrophoregram sorbic acid: potential, $\mathrm{mAU}-\tau, \mathrm{min}$ ]

кое разделение осуществляли в кварцевом капилляре с ведущим электролитом $\left(7.5 \mathrm{mmol} / \mathrm{dm}^{3}\right.$ раствор пара-аминобензойной кислоты), обеспечивающим детектирование кислоты в косвенном варианте, который применяется для регистрации компонентов, не имеющих собственного поглощения в УФ-диапазоне [11]. При разделении непоглощающие ионы пробы замещаются строго эквивалентно поглощающими ионами ведущего электролита, и в зоне детектирования наблюдается уменьшение оптической плотности. На электрофореграмме появляются отрицательные пики, площади которых пропорциональны концентрациям определяемых ионов. Требуемое значение $\mathrm{pH}$ ведущего электролита (5.75) достигается при добавлении к нему раствора гистидина и $0.12 \mathrm{mmol} / \mathrm{dm}^{3}$ тетрадецилтриметиламмония бромида.

В результате проведенных исследований нами установлена возможность эффективного межфазного распределения сорбиновой кислоты в системе на основе сополимера $\mathrm{N}$-винилформамида и 1-винил-3,5-диметилпирозола. Рассчитанные количественные характеристики экстракции сорбиновой кислоты позволяют применять сополимеры с целью извлечения и определения аналита в присутствии других компонентов матрицы.

\section{КОНФЛИКТ ИНТЕРЕСОВ}

Авторы декларируют отсутствие явных и потенциальных конфликтов интересов, связанных с публикацией настоящей статьи.

\section{СПИСОК ЛИТЕРАТУРЫ}

1. Люк Э., Ягер М. Консерванты в пищевой промышленности. Свойства и применение. М.: ГИОРД, 2003, $256 \mathrm{c}$.

2. Мокшина Н. Я., Быковский Д. В., Шаталов Г. В., Пахомова О. А. Конденсированные среды и межфазные гранииы, 2013, т. 15, № 4, с. 423-427. URL: http://www. kcmf.vsu.ru/resources/t $15 \quad 42013$ 009.pdf

3. Коренман Я. И. Коэффициенты распределения органических соединений. Справочник. Воронеж: Воронеж. гос. ун-т., 1992, 336 с.

4. Мокшина Н. Я., Быковский Д. В., Шаталов Г. В., Пахомова О. А. Журнал аналитическойхимии, 2016, т. 71, № 2, c. 208-211. DOI: 10.1134/S1061934816020106

5. Шаталов Г. В., Лавлинская М. С., Пахомова О. А., Мокшина Н. Я., Кузнецов В. А. Журнал прикладной химии, 2016, т. 89, вып. 1, с. 112-118. DOI: 10.1134/ S1070427216010225

6. Быковский Д. В., Кузнецов В. А., Мокшина Н. Я., Пояркова Т. Н., Шаталов Г. В. Известия вузов. Химия и химическая технология. 2014, т. 57, № 7, с. 73-77.

7. Мокшина Н. Я., Пахомова О. А., Шаталов Г. В., Косинова И. И. Известия вузов. Химия и химическая технология, 2019, т. 62, № 1, с. 4-10. DOI: $10.6060 /$ ivkkt.20196201.5763

8. Быковский Д. В., Мокшина Н. Я., Пахомова О. А., Шаталов Г. В., Лавлинская М. С. «Полимеры-2017», тезисы докладов VII Всероссийской Каргинской конференции, 13-17 июня 2017 г., Москва, 2017, с. 262.

9. Кирш Ю. Э. Поли-N-винилпирролидон и другие поли-N-виниламиды. М.: Наука, 1998, 254 с.

10. Коренман Я. И., Зыков А. В., Мокшина Н. Я., Быковский Д. В., Шаталов Г. В. Журнал физической химии, 2011, т. 85, № 11, с. 2142-214.

11. Карцова Л. А. Проблемьг аналитическойхимии. Том 18. Капиллярный электрофорез. М.: Наука, 2014, 438 с. 


\title{
INTERPHASE DISTRIBUTION OF SORBIC ACID DURING EXTRACTION BY COPOLYMERS OF N-VINYLFORMAMIDE AND 1-VINYL-3,5-DIMETHYLPYRAZOL
}

\author{
(C) 2019 N. Ya. Mokshina*1, O. A. Pakhomova ${ }^{2}$, G. V. Shatalov ${ }^{3}$, D. P.Tarasov ${ }^{1}$ \\ ${ }^{1}$ Department of Chemistry and Physic, Military Educational and Scientific Center of the Air Force \\ «N.E. Zhukovsky and Y.A. Gagarin Air Force Academy» (Voronezh) \\ 54 a, Bol'shevikov str., 394064 Voronezh, Russian Federation \\ ${ }^{2}$ Bunin Yelets State University \\ 28, Kommunarov str., 399770 Yelets, Lipetsk region, Russian Federation \\ ${ }^{3}$ Voronezh State University \\ 1, Universitetskaya pl., 394018 Voronezh, Russian Federation
}

\begin{abstract}
Purpose. The paper seeks to determine the extraction characteristics of sorbic acid using a copolymer of N-vinylformamide and 1-vinyl-3,5-dimethylpyrazole as an extractant. The complexation process in the analyte-copolymer system is studied, and a method for finding a preservative by means of capillary electrophoresis is suggested.

Methods and methodology. The extraction of sorbic acid was carried out using a water-soluble copolymer obtained by radical co-polymerization in dioxane. Using common formulas, the distribution coefficients and the degree of extraction of the analyte were calculated for a single extraction in the presence of a saliver - a saturated solution of ammonium chloride.

Results. The conditions for the most efficient extraction of sorbic acid were determined: the characteristic viscosity of the polymers, the concentration of the polymer solution and the analyte, the volume ratio of the phases, the ratio of the molar fractions of N-vinylformamide to 1-vinyl-3,5dimethylpyrazole. The extraction characteristics of the interfacial distribution of sorbic acid between the water-salt solution and the extractant were calculated. The concentration of the co-polymer and the ratio of the volumes of the equilibrium phases at which the maximum degree of sorbic acid extraction is achieved were determined. It was observed that due to the formation of hydrogen bonds during the self-association of molecules, an increase in the concentration of sorbic acid may not lead to an increase in the degree of its extraction. To determine the sorbic acid after the extraction, an external standard method was used including the construction of multi-point calibration curves.

Conclusions. The dependence of the interphase distribution on the structure of the analyte, as well as the complex-forming ability of N-vinylformamide copolymer with 1-vinyl-3,5-dimethylpyrazole as applied to organic acids, was established. The applied extraction systems based on N-vinylformamide copolymers are characterized by environmental and economic feasibility, and good metrological parameters. The calculated quantitative characteristics of the extraction of sorbic acid allow using copolymers to extract and determine the analyte in the presence of other components of the matrix.
\end{abstract}

Keywords: sorbic acid, extraction, water-soluble copolymer, electrophoretic determination.

\section{CONFLICT OF INTEREST}

The authors declare the absence of obvious and potential conflicts of interest related to the publication of this article.

\section{REFERENCES}

1. Luk E., Yager M. Konservanty v pishevoy promyshlennosti. Svoistva i primenenie. [Preservatives in the Food

$\bar{\triangle}$ Mokshina Nadezhda Ya., e-mail: moksnad@mail.ru
Industry. Properties and Application]. Moscow, GIORD Publ., 2003, 256 p. (in Russ.)

2. Mokshina N. Ya., Bykovskiy D. V., Shatalov G. V., Pakhomova O. A. Condensed Matter and Interphases, 2013, vol. 15, no. 4, pp. 423-427. URL: http://www.kcmf.vsu. ru/resources/t_15_4_2013_009.pdf (in Russ.)

3. Korenman Ya. I. Koeffitsienty raspredeleniya organicheskix soedineny. Spravochnik. [Distribution Coefficients of Organic Compounds. Handbook]. Voronezh, Voronezh State Un-t Publ., 1992, 336 p. (in Russ.) 
4. Mokshina N. Ya., Bykovskiy D. V., Shatalov G. V., Pakhomova O. A. J. of Analyt. Chem., 2016, vol. 71, no. 2, pp. 201-204. DOI: 10.1134/S1061934816020106

5. Shatalov G.V., Luvlinskaya M. S. Pakhomova O. A., Mokshina N. Ya., Kuznetsov V.A. Russian J. of Applied Chem., 2016, vol. 89, no. 1, pp. 112-118. DOI: 10.1134/ S1070427216010225

6. Bykovskiy D. V., Kuznetsov V. A., Mokshina N. Ya., Poyarkova T. N., Shatalov G. V., Izvestiya Vysshikh Uchebnykh Zavedeniy Khimiya Khimicheskaya Tekhnologiya, 2014, vol. 57, no. 7, pp. 73-77. (in Russ.)

7. Mokshina N. Ya., Pakhomova O. A., Shatalov G. V., Kosinova I. I. Izvestiya Vysshikh Uchebnykh Zavedeniy Khimiya Khimicheskaya Tekhnologiya, 2019, vol. 62, no. 1. pp. 4-10. DOI: 10.6060/ivkkt.20196201.5763 (in Russ.)
8. Bykovskiy D. V., Mokshina N. Ya., Pakhomova O. A., Shatalov G. V., Luvlinskaya M. S. «Polymers-2017», Proceedings of the VII Rus. Kargin Conference, June 13-17, 2017, Moscow, 2017, p. 262. (in Russ.)

9. Kirsh Yu. E. Poli-N-vinilpirrolidon $i$ drugie poliNvinilamidy [Poly-N-vinylpyrrolidone and other poly-Nvinyl amides]. Moscow, Nauka Publ., 1998, 254 p. (in Russ.)

10. Korenman J. I., Zykov A.V., Mokshina N. I., Bykovskiy D. V., Shatalov G. V. Russian Journal of Physical Chemistry A, 2011, vol. 85, no. 11, pp. 2000-2004. DOI: $10.1134 / \mathrm{S} 0036024411110185$

11. Kartsova L. A. Problems of Analytical Chemistry. Vol. 18. Capillary Electrophoresis. Moscow, Nauka Publ., 2014, 438 p. (in Russ.)
Мокшина Надежда Яковлевна - д. х. н., профессор кафедры физики и химии, ВУНЦ ВВС «Военно-воздушная академия им. проф. Н. Е. Жуковского и Ю. А. Гагарина», Воронеж, Российская Федерация; e-mail:moksnad@mail.ru. ORCID iD 00000001-8409-024X.

Пахомова Оксана Анатольевна - к. х. н., доцент кафедры химии и биологии, Елецкий государственный университет им. И. А. Бунина, Елец, Липецкая обл., Российская Федерация; e-mail: moksnad@ mail.ru. ORCID iD 0000-0002-1969-2698.

Шаталов Геннадий Валентинович - д. х. н., профессор, кафедра высокомолекулярных соединений и коллоидной химии, Воронежский государственный университет, Воронеж, Российская Федерация; e-mail: vms159@chem.vsu.ru. ORCID iD 0000-0002-8050-2662.

Тарасов Дмитрий Павлович - к. ф.-м. н., доцент кафедры физики и химии, ВУНЦ ВВС «Военновоздушная академия им. проф. Н. Е. Жуковского и Ю. А. Гагарина», Воронеж, Российская Федерация; e-mail: demetriys@mail.ru. ORCID iD 0000-00022630-1085.
Mokshina Nadezhda Ya. - Dr. Sci. (Chem.), Professor, Department of Physics and Chemistry, Military Educational and Scientific Center of the Air Force «N. E. Zhukovsky and Y. A. Gagarin Air Force Academy», Voronezh, Russian Federation; e-mail: moksnad@mail.ru. ORCID iD 0000-0001-8409-024X.

Pakhomova Oksana A. - Cand. Sci. (Chem.), Assistant Professor of the Department of Chemistry and Biology, Bunin Yelets State University, Yelets, Lipetsk region, Russian Federation; e-mail: moksnad@mail.ru. ORCID iD 0000-0002-1969-2698.

Shatalov Gennadiy V. - Dr. Sci. (Chem.), Professor, Department of Polymer Science and Colloids, Voronezh State University, Voronezh, Russian Federation; e-mail: vms159@chem.vsu.ru. ORCID iD 00000002-8050-2662.

Tarasov Dmitriy P. - Cand. Sci. (Phis.), Assistant Professor, Department of Physics and Chemistry, Military Educational and Scientific Center of the Air Force «N. E. Zhukovsky and Y. A. Gagarin Air Force Academy», Voronezh, Russian Federation; e-mail: demetriys@mail.ru. ORCID iD 0000-0002-2630-1085. 